\title{
Assessment of Stress Cognitive Control and Executive Function with Stress Control Rating Scale (ECOSTRESS) and Low Resolution Brain Electromagnetic Tomography (LORETA) (In Portuguese People in Situations of Unemployment and Economic Insufficiency)
}

\author{
Eduardo Gonçalves' ${ }^{1}$, Marco Moniz ${ }^{1,2}$, Saul Neves Jesus ${ }^{2}$ \\ ${ }^{1}$ Department of Psychiatry and Mental Health, Hospital Center of Algarve, Faro, Portugal \\ ${ }^{2}$ Research Center for Spatial and Organization Dynamics (CIEO), University of Algarve, Faro, Portugal \\ Email: eduar.goncalves@gmail.com
}

Received 10 February 2016; accepted 28 March 2016; published 31 March 2016

Copyright (C) 2016 by authors and Scientific Research Publishing Inc.

This work is licensed under the Creative Commons Attribution International License (CC BY).

http://creativecommons.org/licenses/by/4.0/

(c) (i) Open Access

\begin{abstract}
This article reviews the constructs of stress, appraisal, coping, according to a transactional perspective, and executive function, and presents a stress control rating scale (ECOSTRESS), which design is founded in these constructs. This psychometric tool is useful in the assessment of cognitive control of stress, correlated with the function of dorsolateral prefrontal cortex. It has been validated for its use in the assessment of Portuguese people in situations of stress related to unemployment and economic insufficiency. Also, within the context of the cognitive control of stress, it is highlighted the usefulness of low resolution brain electromagnetic tomography (LORETA).
\end{abstract}

\section{Keywords}

Stress, Anxiety, Depression, Mania, Economic Insufficiency, Executive Function, Anterior Cingulate Cortex, Dorsolateral Prefrontal Cortex, Stress Control Rating Scale (ECOSTRESS), Low Resolution Brain Electromagnetic Tomography (LORETA), Neurofeedback

How to cite this paper: Gonçalves, E., Moniz, M. and Jesus, S.N. (2016) Assessment of Stress Cognitive Control and Executive Function with Stress Control Rating Scale (ECOSTRESS) and Low Resolution Brain Electromagnetic Tomography (LORETA) (In Portuguese People in Situations of Unemployment and Economic Insufficiency). Open Journal of Psychiatry, 6, 158-164. http://dx.doi.org/10.4236/ojpsych.2016.62019 


\section{Introduction}

In this article, it is proposed a stress control rating scale (ECOSTRESS), which is already validated for Portuguese population. Its construction is based in the construct of stress, according to the transactional perspective defined by Lazarus and Folkman, and of executive function. It is also highlighted the utility of low resolution brain electromagnetic tomography (LORETA) in the assessment of stress control by the dorsolateral prefrontal cortex.

\subsection{Stress, Appraisal, Coping, Emotion, Anxiety, Depression and Neurobiological Correlates}

A situation is appraised as irrelevant to the personal well-being if the motivational relevance is low. High motivational relevance in combination with motivational congruence (situation appraised as important and desirable) defines the circumstances as beneficial and can evoke feelings of happiness [1] [2]. Beneficial appraisals of self-accountability evoke feelings of pride. Beneficial appraisals of hetero-accountability evoke feelings of gratitude. High motivational relevance appraisals and low motivational congruence (important and undesirable situation) define the circumstances as stressful. Self-accountability appraisals combined with primary appraisals of stress evoke guilt, shame (self-directed negative emotions). Hetero-accountability appraisals combined with primary appraisals of stress evoke anger. Appraisals of high problem-focused coping potential combined with primary appraisals of stress define the circumstances as an opportunity, indicate that the person has potential abilities to change the circumstances, as to make them more syntonic to his/her wishes, and evoke feelings of challenge, determination that motivate the individual to get involved in the situation and work to make it more desirable [1] [2]. Appraisals of low problem-focused coping potential combined with primary appraisals of stress define the circumstances as harm, indicate that person is in a precarious situation, for which little can be done to improve it and evoke feelings of sadness and resignation, that motivate the individual to seek help and possibly to resign on the harmful situation, allowing his/her involvement in another [2] [3]. Appraisals of high emotion-focused coping potential, i.e., appraisals of competency to adapt to circumstances which do not function as desired, allow the person to keep calm, in conditions appraised as stressful. Appraisals of low emotion-focused coping potential, i.e., appraisals of incompetence to adapt to circumstances which do not function as desired, define the situation as a threat and evoke feelings of fear, anxiety, motivating the person to be vigilant and to take care in an attempt to prevent undesired results [2]. Stress results from combined appraisals of high motivational relevance and motivational incongruence, i.e., it occurs when a person evaluates his/her circumstances as important but undesirable. Thus, stress can be defined as a subjectively important discrepancy between what one wants (motivational state) and what one has, in a given situation (situational state); then, coping consists of individual efforts to reduce the magnitude of this discrepancy. In short, acting on the circumstances for change it in order to put them more in line with one wishes corresponds to problem-focused coping [4]; acting on the desires/wishes or beliefs so that the conditions become more desirable, without change, which can be achieved by strategies as reprioritizing goals [3], appraising circumstances under a more (emotional) positive perspective, reinterpreting circumstances relevance with respect to the goals, corresponds to emotion-focused coping, as described by Lazarus and Folkman [4], and more appropriately, to accommodative coping, as defined by Walker et al. [5]. Goldstein showed that damage to the left hemisphere was more likely to cause a catastrophic-depressive reaction in psychiatric patients than damage to the right hemisphere [6]. Sackeim et al., reviewing 109 cases of pathological laugh and crying, found evidence suggesting a differential hemispheric specialization for positive and negative emotions. In general, damage to left hemisphere led to the onset of depressive symptoms in psychiatric patients. On the other hand, damage to the right hemisphere was more frequently associated to a pathological laughing condition [7]. Bear verified that lesions to the right hemisphere tend to cause an indifference towards one's own illness, as well as financial difficulties, interpersonal conflicts [8]. In order to deal with these results, a new brain asymmetry model was proposed by Davidson, the valence hypothesis, which proposes that the pattern of hemispheric dominance depends on the emotional valence of the stimulus: the left hemisphere is dominant for processing positive emotions whereas the right hemisphere is dominant for pro- cessing negative emotions [9]. Recent neuroimaging and therapeutic transcranial magnetic stimulation studies suggest imbalance between left and right dorsolateral prefrontal cortex (DLPFC) in major depressive disorder: left DLPFC hypoactivity is associated with negative emotional judgment [10]. Rapid therapeutic response to anodal transcranial direct current stimulation of right DLPFC treats acute mania [11]. 


\subsection{Executive Function and Neurobiological Correlates}

Executive functioning (EF) can be defined as forming, maintaining and shifting mental sets, corresponding to the abilities to reason and generate goals and plans, maintain focus and motivation to follow through with goals and plans, and flexibly to alter goals and plans in response to changing contingencies. EF allows higher organisms to make choices and to engage in purposeful, goal-directed and future-oriented behavior, and confers an evolutionary advantage by freeing an organism from innate, hard-wired drives and reflexes, as well as from over-practiced, over learned and pre-potent responses, coming "on line" only when the novelty and/or complexity of a given situation precludes an automatic, routine response. EF has been described as being associated with brain Prefrontal Cortex (PFC). PFC can be divided into three main convexities: Dorsolateral PFC (DLPFC), often described as the substrate of working memory; Superomedial PFC (SMPFC)-including the Anterior Cingulate Cortex (ACC) - often described as the substrate for sustained attention, response selection, and motivation; Ventral/Inferior PFC—divided into Orbitofrontal (OFPFC) and Ventromedial (VMPFC), often described as the substrate for inhibition, social appropriateness, and sensitivity to rewards and punishments. The most anterior portions of the frontal lobes, known as the frontal pole, which includes anterior portions of the DLPFC and VMPFC, have a role in morality, empathy and higher order integration of EF. Additionally, left PFC is associated with initiation of responses and processing of information that is verbal, concrete or detail-oriented, and right PFC is associated with inhibition of responses and processing of information that is visual-spatial, abstract or connotative and gestalt-oriented. The PFC is not the only brain area involved in EF (most EF processes depend on the integrity of complex networks rather than a single frontal lobe region). A tripartite model of EF is used, which consists of three entities: the abilities to form maintain and shift mental set. These components correspond with the abilities to reason and problem solve, maintain motivation to follow through with a response in the absence of external structure, and alter goals and plans as needed in response to changing contingencies (individuals with a strength in the area of forming mental set generate new ideas easily and readily come up with plans or solutions to problems). Experimental tasks for the assessment of EF can generally be divided into three main categories: cognitive control, working memory, and emotional decision making. Switching tasks, as the computer-administered Stroop tasks, are the most typical examples of cognitive control measures. These tasks share in common the need to select one of several possible responses to a given stimulus (conflict resolution). This often involves, among others, inhibiting a response that is pre-potent; the pre-potent status of a given response is either due to the response being previously over-learned (on a Stroop task, word reading is pre-potent to naming the color of print) or due to being primed as part of the experimental procedure (on Wisconsin Card Sorting Test, WSCT, during the switching task, a participant generates a particular response on one trial, but that same response is incorrect on the subsequent trial). Working memory tasks only require that participants hold information in working memory, without any conflict resolution requirement (Tower of Hanoi/London, Corsi Block Test). The emotional decision making tasks, such as the Iowa Gambling Task (IGT), require that participants weigh, toward a specific goal, the relative contributions of rewards and punishments (in IGT, participants are instructed to select cards that are presented face down in four decks, with the goal of winning as much money as possible; selecting cards from two of the decks—-the "bad" decks-results in large winnings but even larger losses, while selecting cards from the other two decks-the "good" decks-results in small winnings but even smaller losses). Mental set formation, i.e., the generation of short-term and long-term objectives, through planning and reasoning, using the neurocognitive processes of focusing attention, generativity, memory retrieval, working memory, sequencing, requires the integrity of DLPFC, which lesion determines a dysexecutive disorganized neuro-behavioral syndrome. Mental set maintenance, i.e., the execution of short-term and long-term goals, through implementation (follow-up and monitoring), using the neurocognitive processes of response initiation, response selection and conflict resolution, selective attention, self-monitoring and attentional vigilance, requires the integrity of SMPFC, which lesion determines an apathetic neurobehavioral syndrome. Mental set maintenance through social appropriateness, judgment, using the neurocognitive processes of response inhibition and discrepancy detection, requires the integrity of VMPFC and OFPFC, which lesion determines a disinhibited or psychopathic neurobehavioral syndrome. Mental set shifting, i.e., the change, in a flexible manner, of goals and plans, in adaptive response to changing contingencies, through problem solving, using the neurocognitive processes of discrepancy detection, cognitive flexibility, attentional shifting, generativity, memory retrieval and working memory, requires the integrity of DLPFC, which lesion determines a dysexecutive perseverative neurobehavioral syndrome [12] (Table 1). 
Table 1. Lesions of dorsolateral prefrontal cortex (DLPFC), orbitofrontal cortex (OFPFC), ventromedial prefrontal cortex (VMPFC) and superomedial prefrontal cortex (SMPFC) and corresponding neurobehavioral syndromes. Neurocognitive processes most frequent used in each overarching purpose are signaled (with 1, 2, 3), being 1 for set formation, 2 for set maintenance, 3 for set shifting; $1 \mathrm{a}$ and 3 are assessed by Wisconsin Card Sorting Test, which nonexecutive components are visual-spatial ( 3 is also assessed by Tower of Hanoi/London, Corsi Block Test, which nonexecutive components are visual-spatial); $1 \mathrm{~b}$ is assessed by Tower of Hanoi/London, Corsi Block Test; 2b, 2c and 2d are assessed by Stroop color and word test, which nonexecutive components are visual-spatial, language and processing speed; $2 \mathrm{a}$ and $2 \mathrm{~d}$ are assessed by go/no-go tasks, and Iowa Gambling Task (IGT) assesses emotional decision making. The syndrome signaled with I concerns brain information management (noisy information); syndrome signaled with II concerns brain energy management (energy deficit); syndrome signaled with III concerns brain energy management (energy excess); syndrome signaled with IV concerns brain information management (reverberant information) (adapted from Suchy, 2009 [12]).

\begin{tabular}{|c|c|c|c|}
\hline Overarching purpose & Cognitive skill & Neurocognitive processes & $\begin{array}{l}\text { Corresponding } \\
\text { neurobehavioral syndrome }\end{array}$ \\
\hline $\begin{array}{l}\text { Set Formation } \\
\text { (Generating short-term } \\
\text { and } \\
\text { long-term goals) }\end{array}$ & $\begin{array}{l}\text { Planning and } \\
\text { reasoning }\end{array}$ & $\begin{array}{l}\text { Focusing attention } \\
\text { Generativity (1a) } \\
\text { Memory retrieval } \\
\text { Working memory (1b) } \\
\text { Sequencing }\end{array}$ & $\begin{array}{l}\text { Dysexecutive/Disorganized } \\
\text { (primarily lesions in DLPFC) } \\
\text { (I) }\end{array}$ \\
\hline \multirow{3}{*}{$\begin{array}{l}\text { Set Maintenance } \\
\text { (Executing short-term } \\
\text { and } \\
\text { long-term goals) }\end{array}$} & Organization & $\begin{array}{l}\text { Sequencing } \\
\text { Working memory }\end{array}$ & \\
\hline & Follow-through & $\begin{array}{l}\text { Initiation (2a) } \\
\text { Response selection/conflict resolution } \\
\text { (2b) } \\
\text { Selective attention } \\
\text { Self monitoring } \\
\text { Attentional vigilance (2c) }\end{array}$ & $\begin{array}{l}\text { Apathetic } \\
\text { (primarily lesions in SMPFC) } \\
\text { (II) }\end{array}$ \\
\hline & $\begin{array}{l}\text { Social } \\
\text { appropriateness, } \\
\text { judgment }\end{array}$ & $\begin{array}{l}\text { Inhibition (2d) } \\
\text { Discrepancy detection }\end{array}$ & $\begin{array}{l}\text { Disinhibited or Psychopathic } \\
\text { (primarily lesions in VMPFC and OFPFC) } \\
\text { (III) }\end{array}$ \\
\hline $\begin{array}{l}\text { Set Shifting } \\
\text { (Altering short-term } \\
\text { and } \\
\text { long-term goals in } \\
\text { response to changes in } \\
\text { situations and } \\
\text { contexts) }\end{array}$ & Problem-solving & $\begin{array}{l}\text { Discrepancy detection } \\
\text { Cognitive flexibility (3) } \\
\text { Attentional shifting } \\
\text { Generativity } \\
\text { Memory retrieval } \\
\text { Working memory }\end{array}$ & $\begin{array}{l}\text { Dysexecutive/Perseverative } \\
\text { (primarily lesions in DLPFC) } \\
\text { (IV) }\end{array}$ \\
\hline
\end{tabular}

\subsection{Economic Insufficiency/Poverty and Unemployment}

The lack of opportunities causes poverty, reduced accessibility to resources and a greater likelihood of life events with traumatogenic potential. By acting through stressors agents of socio-economic nature, such as unemployment and the difficulty of access to housing, it is much more likely that poverty precedes mental disorders, such as anxiety and depression, and constitutes an important risk factor for mental illness [13]. Within this context, it was designed a rating scale for stress assessment of people in situations of unemployment and economic insufficiency, which it will be briefly described.

\section{Stress Control Rating Scale (ECOSTRESS)}

A previous cognitive debriefing was performed. All subjects gave informed consent. Sampling data was collected between 17 and 23 October 2013. The sample consists of 33 subjects, 48\% female. The mean value of age is 53.8 years. All the persons are Portuguese and $97 \%$ of the subjects live in the Portuguese city of Olhão. $24 \%$ of the subjects are single, $49 \%$ are married, $3 \%$ are separated, $12 \%$ are divorced and $12 \%$ are widowed. The majority of the subjects hasn't superior scholar habilitations. $40 \%$ of the subjects are unemployed, $12 \%$ are retired and 6\% are pensioners. The mean value of monthly net/liquid income is 337 euros (with a dispersion of values of $69 \%$ ). $24 \%$ of subjects say that past financial difficulties were mild, $36 \%$ of the subjects answer that financial difficulties were moderate and $40 \%$ considered them severe. $94 \%$ of participants evaluate that their financial situation had worsened over the past two years, and $97 \%$ evaluate that their financial situation will worsen in the coming years. 52\% of participants haven't any chronic disease, and the remaining subjects relate to 
present: cancer; diabetes; ischemic heart disease; arrhythmia; hypercholesterolemia; hypertension; myasthenia gravis [14]. Stress Control Rating Scale (ECOSTRESS) is an ordinal Likert scale with five possible answers ("1" to "5”): 1—“I disagree almost entirely” (in Portuguese language: "Discordo quase na totalidade”); 2-“I disagree more than I agree" (Portuguese language: "Discordo mais do que concordo"); 3- “ I neither agree nor disagree” (in Portuguese language: "Não concordo nem discordo"); 4- “I agree more than I disagree” (in Portuguese language: "Concordo mais do que discordo"); 5-“I agree almost entirely" (in Portuguese language: "Concordo quase na totalidade"). The responses concern the subject's evaluation of his/her present/actual situation of unemployment and economic insufficiency. It is initially composed of 13 items, and, in its final version, 10 items. For each item is explained the respective theoretical foundation/framework (construct). Item 1 is "I appraise my resources and skills to fulfill my wishes" (in Portuguese language: "Avalio os meus recursos e competências para concretizar os meus desejos"). The sense of control subject-situation transaction is obtained through appraisal/monitoring of the characteristics of the desired situation and the personal resources and competencies, aiming an adjusted transaction. Item 2 is "I wish my situation which is even beneficial to my health" (in Portuguese language: "Desejo a minha situação que até é benéfica para a minha saúde”). The wish of the situation appraised as beneficial, corresponding to an adjusted adequacy (no discrepancy) between stress and coping, may evoke the emotion of happiness (high motivational congruence and relevance) and fit the concept of eustress (stress associated with a situation appraised as beneficial, challenging). Item 4 is "I adapt myself to my situation” (in Portuguese language: “Adapto-me à minha situação”). The adaptation to the situation may evoke the emotion of calm, corresponding to high potential of emotion-focused coping and to an adequate function of left and right frontal cortices. Item 5 is "I am responsible for my situation" (in Portuguese language: "Responsabilizo-me pela minha situação"). Self-accountability respecting the adjustment of the subject-situation transaction is associated with a greater level of stress control, compared to other-accountability, and has diagnostic power, attending to the correspondent evoked emotions (pride or shame versus gratitude or anger). Item 6 is "I do not change myself or adapt to my situation and I hope for its future improvement" (in Portuguese language: "Não mudo nem me adapto à minha situação e tenho esperança na sua futura melhoria"). A coping strategy modality consists on the adduction of the sense of hope concerning the improvement of the situation, without adaptation to or change it (on the contrary, hopelessness is associated with the appraisal of harm and depression). Item 7 is "I generate other priorities and I change my beliefs to make my situation, at least, less undesirable, at best, more desirable" (in Portuguese language: "Crio outras prioridades e mudo de crenças para tornar a minha situação, no mínimo, menos indesejável, no máximo, mais desejável”). Making the situation, at least, less undesirable, at best, more desirable, may be achieved by establishing priorities and changing (personal) belief system. Item 10 is "I watch an horror movie as well as some of the most gruesome scenes are nothing but fiction" (in Portuguese language: "Assisto a um filme de terror também porque algumas das cenas mais horríveis não passam de ficção"). The control of the evoked emotion of fear, i.e., the control of low potential of emotion-focused coping, corresponds to an adequate activation of left frontal cortex, an appropriate left prefrontal cortex-amigdala top-down control, and the situation is not appraised by the subject as threatening. Item 11 is "I watch a comedy movie also because some of the most laughable scenes take place in reality" (in Portuguese language: "Assisto a um filme de comédia também porque algumas das cenas mais risíveis ocorrem na realidade”). The control of the evoked emotion of euphoria/excitation is associated with an appropriate activation of right frontal cortex. Item 12 is "I cope with my situation with aids (personal; non-personal/activities)" (in Portuguese language: "Lido com a minha situação com ajudas (pessoais; não pessoais/actividades)"). Coping strategies aiming the control of the subject-situation transaction consist, in summary, on the adduction from or the abduction to the subject of aids, present in his/her environment, personal or not personal ones (mater, energy, information), and requires the integrity of subject's executive function and its neurobiological correlates (prefrontal cortex). Item 13 is "I create, maintain and timely modify mental scenarios/sets and plans to solve problems" (in Portuguese language: "Crio, mantenho e modifico atempadamente cenários e planos mentais para solucionar problemas"). To the control of the subject-situation transaction through executive function, that is, generating and executing (implementing) short- and long-term goals and shifting goals and plans in adaptive response to contingency changes corresponds an adequate functionality of the prefrontal cortex (PFC), particularly SMPFC and DLPFC (cognitive flexibility may be associated with adequate resilience competencies, dependent on the functional integrity of the DLPFC). In summary, the removal of items 3, 8 and 9, from the 13-item ECOSTRESS initial version, resulted in a Cronbach's alpha value of. 639, in its 10-item final version, so these ten variables measure a single dimension. Additional tests indicate that there are no items correlated negatively with the scale, 
but item 10 contributes to the fact that the value of Cronbach's alpha value is not higher [15]-[17] (Table 2).

\section{Monitoring Brain Activity and Neurofeedback with Low Resolution Brain Electromagnetic Tomography (LORETA)}

Low Resolution Brain Electromagnetic Tomography (LORETA) method uses brain electrical activity based on surface electroencephalography. Markela-Lerenc et al. [18] propose that the ACC detects the need for EF control and signals the PFC to run the control. DLPFC and ACC are instrumental in EF, and are physiologically connected and jointly activated in functional imaging studies (Figure 1).

A brain network has been implicated in top-down attentional control, including left DLPFC and dorsal ACC

Table 2. Internal consistency indicators of stress control rating scale (ECOSTRESS).

\begin{tabular}{|c|c|c|}
\hline & $\begin{array}{l}\text { Correct total } \\
\text { item correlation }\end{array}$ & $\begin{array}{l}\text { Cronbach's alpha } \\
\text { without the item }\end{array}$ \\
\hline Item 1. "I appraise my resources and skills to fulfill my wishes" & 0.121 & 0.642 \\
\hline Item 2. "I wish my situation which is even beneficial to my health" & 0.253 & 0.627 \\
\hline Item 4. "I adapt myself to my situation" & 0.547 & 0.567 \\
\hline Item 5. "I am responsible for my situation” & 0.260 & 0.629 \\
\hline Item 6. "I do not change or adapt myself to my situation and I hope for its future improvement" & 0.296 & 0.616 \\
\hline $\begin{array}{l}\text { Item 7. "I generate other priorities and I change my beliefs to make my situation, at least, less } \\
\text { undesirable, at best, more desirable" }\end{array}$ & 0.345 & 0.606 \\
\hline $\begin{array}{l}\text { Item 10. "I watch an horror movie as well as some of the most gruesome scenes are nothing but } \\
\text { fiction" }\end{array}$ & 0.176 & 0.649 \\
\hline $\begin{array}{l}\text { Item 11. "I watch a comedy movie also because some of the most laughable scenes take place in } \\
\text { reality" }\end{array}$ & 0.370 & 0.604 \\
\hline Item 12. "I cope with my situation with aids (personal; non-personal/activities)" & 0.302 & 0.614 \\
\hline Item 13. "I create, maintain and timely modify mental scenarios/sets and plans to solve problems" & 0.482 & 0.577 \\
\hline
\end{tabular}

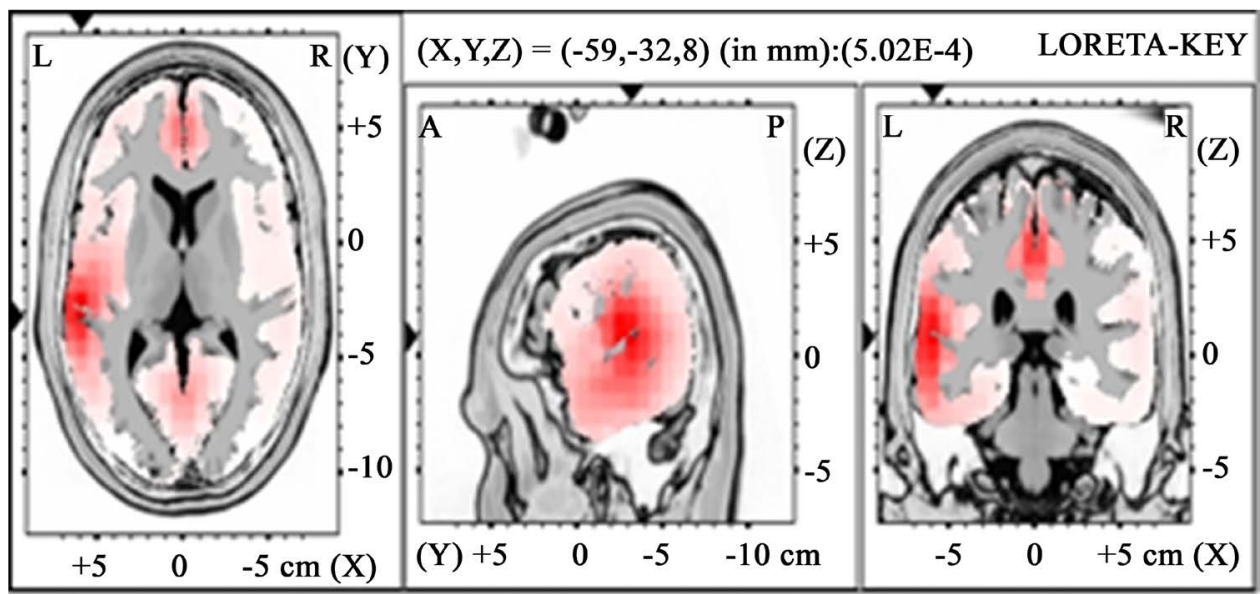

Figure 1. Short clinical vignette illustrating the diagnostic and therapeutic utility of low resolution brain electromagnetic tomography (LORETA). A 45 years old female patient complains from insidious onset of memory faults, anxiety/depression and sporadic auditory-verbal hallucinations, which have been interfering with her family life and professional performance. Neuropsychology assessment allowed to highlight, among other alterations in executive function, disruption of working memory. Computerized Tomography brain scan revealed nonspecific slight accentuation of frontal and temporal cortical sulci, and electroencephalography examination showed oscillatory activity, within theta band (4 - $8 \mathrm{~Hz}$ ), at left temporal lobe. LORETA (with center coordinates, in $\mathrm{mm}, x=-59, y=-32, z=8$ ) showed activation from, among other brain areas, superomedial prefrontal cortex/anterior cingulate cortex (SMPFC/ACC) and left temporal cortex. It is inferred the existence of the inefficiency of left fronto-temporal top-down control (mainly, not performed by dorsolateral prefrontal cortex (DLPFC)), not inhibiting theta range neuronal oscillatory activity (from neurodegenerative nature, as demonstrated by magnetic resonance imaging brain scan). 
[19]. LORETA based neurofeedback is used in the treatment of various neurologic (traumatic brain injury, epilepsy) and psychiatric disorders [20].

\section{Conclusion}

Dorsolateral prefrontal cortex (DLPFC) is instrumental in executive function (EF). Its dysfunction/injury is related to working memory malfunction (as present in schizophrenia), decreased cognitive stress control, not active coping strategies, decreased resiliency competencies, dysexecutive disorganized and perseverative syndromes, depression (which includes deficit of initiation due to dysfunctional left superomedial prefrontal cortex) and mania (which includes deficit of inhibition due to dysfunctional right orbitofrontal cortex and ventromedial prefrontal cortex). ECOSTRESS and LORETA assess DLPFC functionality, i.e., stress cognitive control.

\section{References}

[1] Smith, C.A. (1991) The Self, Appraisal, and Coping. In: Snyder, C.R. and Forsyth, O.R., Eds., Handbook of Social and Clinical Psychology: The Health Perspective, Pergamon Press, New York, 116-137.

[2] Smith, C.A. and Lazarus, R.S. (1990) Emotion and Adaptation. In: Pervin, L.A., Ed., Handbook of Personality: Theory and Research, Guilford, New York, 609-637.

[3] Rasmussen, H.N., Wrosch, C., Scheier, M.F. and Carver, C.S. (2006) Self-Regulation Processes and Health: The Importance of Optimism and Goal Adjustment. Journal of Personality, 74, 1721-1747. http://dx.doi.org/10.1111/j.1467-6494.2006.00426.x

[4] Lazarus, R.S. and Folkman, S. (1984) Stress, Appraisal, and Coping. Springer, New York.

[5] Walker, L.S., Smith, C.A., Garber, J. and Van Slyke, D.A. (1997) Development and Validation of the Pain Response Inventory for Children. Psychological Assessment, 9, 392-405. http://dx.doi.org/10.1037/1040-3590.9.4.392

[6] Goldstein, K. (1939) The Organism. Academic Book, New York.

[7] Sackeim, H.A., Weiman, A.L., Gur, R.C., Greenberg, M.S., Hungerbuhler, J.P. and Geschwind, N. (1982) Pathological Laughing and Crying: Functional Brain Asymmetry in the Experience of Positive and Negative Emotions. Archives of Neurology, 39, 210-218. http://dx.doi.org/10.1001/archneur.1982.00510160016003

[8] Bear, D.M. (1983) Hemispheric Specialization and the Neurology of Emotion. Neurological Review, 40, $195-202$. http://dx.doi.org/10.1001/archneur.1983.04050040025003

[9] Davidson, R.J. (1995) Cerebral Asymmetry, Emotion, and Affective Style. In: Davidson, R.J. and Hughdahl, K., Eds., Brain Asymmetry, MIT Press, Massachusetts, 361-387.

[10] Grimm, S., et al. (2008) Imbalance between Left and Right Dorsolateral Prefrontal Cortex in Major Depression Is Linked to Negative Emotional Judgment: An fMRI Study in Severe Major Depressive Disorder. Biological Psychiatry, 63, 369-376. http://dx.doi.org/10.1016/j.biopsych.2007.05.033

[11] Schestatsky, P., et al. (2013) Rapid Therapeutic Response to Anodal tDCS of Right Dorsolateral Prefrontal Cortex in Acute Mania. Brain Stimulation, 6, 701-703. http://dx.doi.org/10.1016/j.brs.2012.10.008

[12] Suchy, Y. (2009) Executive Functioning: Overview, Assessment, and Research Issues for Non-Neuropsychologists. Annals of Behavioral Medicine, 37, 106-116. http://dx.doi.org/10.1007/s12160-009-9097-4

[13] Patel, V. and Kleinman, A. (2003) Poverty and Common Mental Disorders in Developing Countries. Bulletin of the World Health Organization, 81, 609-615.

[14] Gonçalves, E., et al. (2015) Mental and Cardiovascular Health of Portuguese Subjects in a Situation of Economic Insufficiency. Open Journal of Psychiatry, 5, 374-385. http://dx.doi.org/10.4236/ojpsych.2015.54042

[15] Anastasi, A. (1990) Psychological Testing. McMillan, New York.

[16] Cronbach, L.J. (1951) Coefficient Alpha and the Internal Structure of Tests. Psychometrika, 16, 297-334. http://dx.doi.org/10.1007/BF02310555

[17] Maroco, J. (2007) Análise Estatística com Utilização do SPSS. 3. ${ }^{a}$ Edição. Edições Sílabo, Lisboa.

[18] Markela-Lerenc, J., et al. (2004) Prefrontal-Cingulate Activation during Executive Control: Which Comes First? Cognitive Brain Research, 18, 278-287. http://dx.doi.org/10.1016/j.cogbrainres.2003.10.013

[19] Silton, R.L., et al. (2010) The Time Course of Activity in Dorsolateral Prefrontal Cortex and Anterior Cingulate Cortex during Top-Down Attentional Control. NeuroImage, 50, 1292-1302. http://dx.doi.org/10.1016/j.neuroimage.2009.12.061

[20] Thornton, K.E. and Carmody, D.P. (2008) Efficacy of Traumatic Brain Injury Rehabilitation: Interventions of QEEGGuided Biofeedback, Computers, Strategies, and Medications. Applied Psychophysiology \& Biofeedback, 33, 101-124. http://dx.doi.org/10.1007/s10484-008-9056-z 